\title{
Effects of Aldosterone, Osteoprotegerin and Fibroblast Growth Factor-23 and Some Biochemical Markers in Chronic Kidney Disease Patients (Stage II-IV) among Patients with or without Cardiovascular Events

\author{
Zeyad A. Ameen ${ }^{*}$, , Shatha H. Ali" and Ali A. Allawi**
}

* Department of Clinical Laboratory Science, College of Pharmacy, University of Baghdad, Baghdad, Iraq. ** Department of Internal Medicine, College of Medicine, University of Baghdad, Baghdad, Iraq.

\section{Abstract}

Chronic Kidney Disease (CKD) is a public health problem and many studies support the link between kidney dysfunction and cardiovascular events. Aldosterone has been shown for decades that a plasma aldosterone concentration is elevated in CKD. Whilst, Osteoprotegerin (OPG), after its capacity to protect bone, also osteoprotegerin is elevated in patients with chronic kidney disease (CKD), where it could predict the deterioration of kidney function, cardiovascular, vascular events and all-cause mortality. On the other hand, fibroblast growth factors (FGFs), in patients with CKD, its levels seem to increase progressively as kidney function worsens. The aim of the present study is to assess the correlations between serum osteoprotegerin, aldosterone and fibroblast growth factor-23 levels in patients with chronic kidney disease stage (II-IV) with and without cardiovascular events.

The study includes fifty-nine patients with chronic kidney disease(CKD) and according to CKDEPI /Creatinine/ 2009 equation to be allocated as stage II-IV, patients were divided into three groups: Group1 (29 patients) with chronic kidney disease(CKD) stage (II-IV) with cardiovascular events. Group2 (30 patients) with chronic kidney disease stage (II-IV) without cardiovascular event, to be compared with Group 3(23 apparently healthy subjects), age and sex matched to that of patients. Serum obtained from their blood specimens to measure; glucose, urea, creatinine, calcium, phosphate, sodium, potassium, aldosterone, FGF-23, Osteoprotergen.

Data analysis showed that fasting serum glucose levels of CKD patients (with and without CV disorder) had significantly higher values as compared to the controls (76.5\% and $29 \%$ respectively). Serum Aldosterone, FGF-23, OPG levels were presented with no significant variation among studied groups with CV events or those without CV events.

Keywords:CKD, Aldosterone, Osteoprotegerin,FGF-23.

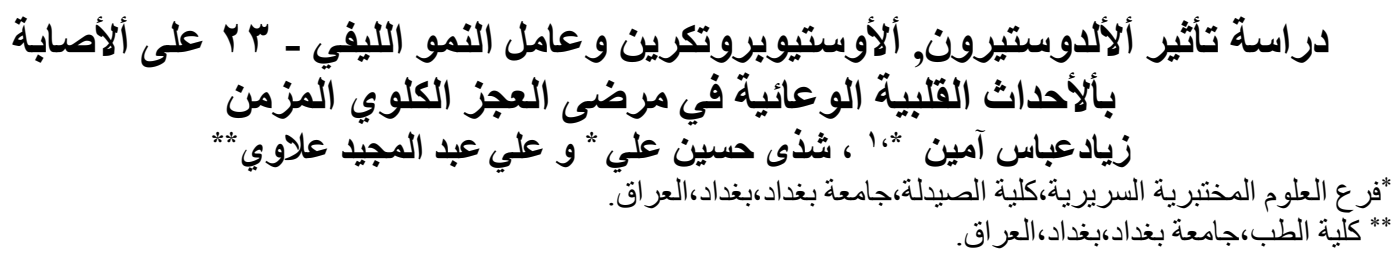

الخلاصة

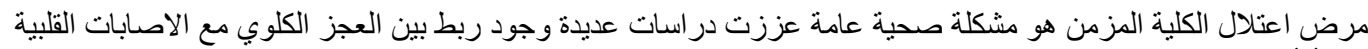

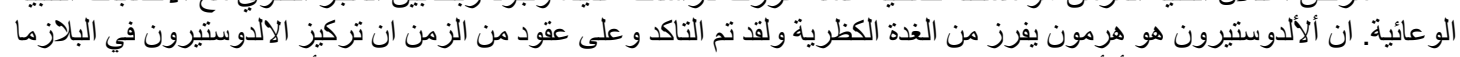

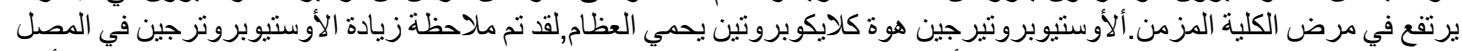

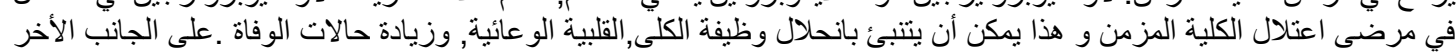

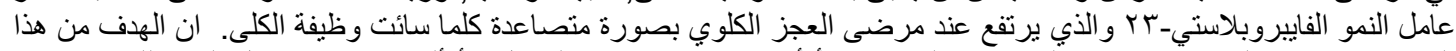

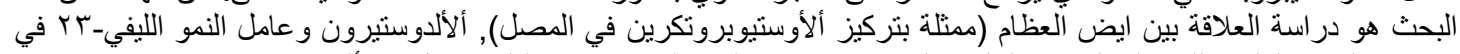

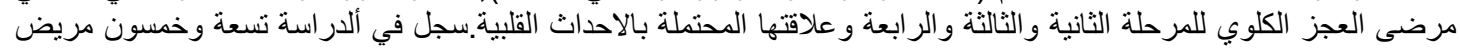

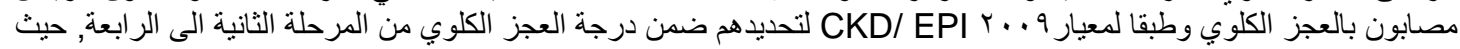

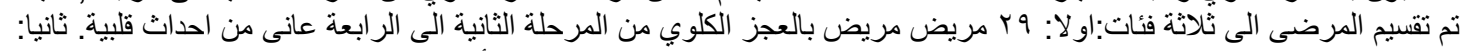

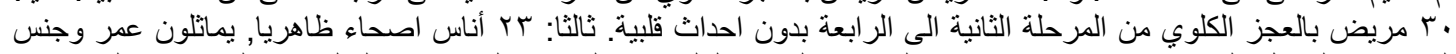

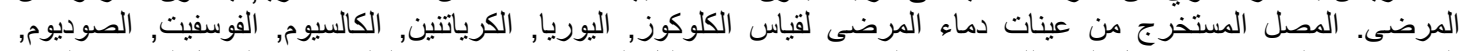

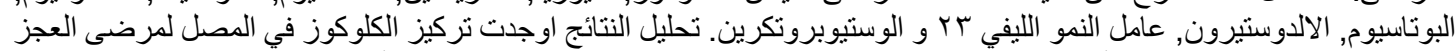

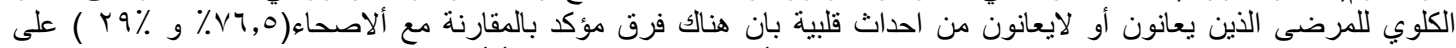

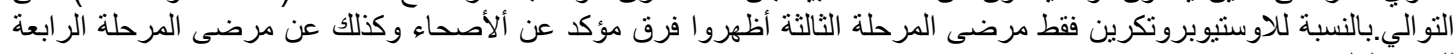
للعجز الكلوي. الكلمات المفتاحية: مرضى الفشل الكلوي ، ألألاوستيرون ، ألأوستيوبروتكرين ، عامل النمو الليفي بr.

${ }^{1}$ Corresponding author E-mail: zeyad1982ph@yahoo.com

Received: 27/ 8 / 2018

Accepted: 12 / $11 / 2018$

Iraqi Journal of Pharmaceutical Sciences 


\section{Introduction}

CKD is a public health problem, that results from the decrease in renal function represented by GFR for a period of three months or more which is associated with severe cardiac outcomes and high mortality rate ${ }^{(1)}$.

Mortality of CKD adjusted for comorbidity, race, gender, age and previous hospitality for CKD patients indicate an obvious decline in rates since 1995 may reflect to some extent the increased recognition of CKD as this confirmed by increasing number of patients carrying the diagnosis ${ }^{(2)}$.

Aldosterone is an adrenal hormone that plays a pivotal role in electrolyte and fluid homeostasis and thus control of blood pressure. It has been shown for decades that a plasma aldosterone concentration is elevated in $\mathrm{CKD}^{(3)}$

Regulatory systems that are normally involved in homeostasis, can take on maladaptive roles. This paradoxical situation has been convincingly illustrated in heart failure. The evidence is more obvious with respect to the beneficial effects of sympathetic and renin-angiotensin-aldosterone system blockade (4) Although the success of medications such as angiotensin-converting enzyme (ACE) inhibitors was initially attributed to hemodynamic actions unloading the left ventricle, additional direct cellular effects on cardiac remodeling have been discovered (5). In the case of chronic progressive renal disease, substantial evidence attests to the efficacy of ACE inhibitors and, more recently, angiotensin receptor blockers in slowing the progression of both experimental and clinical renal disease ${ }^{(6)}$.

Osteoprotegerin (OPG) is a glycoprotein, in addition to its capacity to protect bone. It is produced in many tissues including lung, bone, kidney, vasculature, heart, and placenta ${ }^{(7,8)}$. It was shown that serum OPG is elevated in patients with nondiabetic and diabetic chronic kidney disease (CKD), where it could predict the deterioration of kidney function, cardiovascular, vascular events and all-cause mortality ${ }^{(9)}$.Consistent to these results, it is recently reported that elevated OPG is combined with elevated risk of rapid renal decline, renal disease hospitalization, and/or deaths in elderly women $^{(9)}$.

In CKD patient vascular calcification (VC) is recognized as a strong predictor of cardiovascular mortality ${ }^{(10)}$.

On the other hand, fibroblast growth factors (FGFs) that signal through FGF receptors (FGFRs) can regulate a wide domain of biological functions ${ }^{(11)}$. As the central target organ of FGF-23 appears to be the kidney, where tubular phosphate reabsorption and 1alpha-hydroxylase expression are suppressed. These features raised the question which role FGF-23 might play in dialysis patients (CKD stage V), ${ }^{(12)}$. In patients with CKD, FGF-23 concentrations are constitutively elevated and increase progressively as kidney function worsens, likely as an appropriate compensation to help maintain normal serum phosphate concentrations in the face of declining nephron mass. At the level patients reach end-stage renal disease, where FGF-23 concentrations are often increased 100-to 1000 -fold above the normal range, whereas serum phosphate concentrations are only modestly increased or even normal ${ }^{(13)}$. FGF23 is associated with heart failure and mortality in patients with or without chronic kidney disease, Because FGF23 is regulated by phosphate (albeit in an indirect manner) and phosphate is correlated with mortality and heart failure, it is possible that this association is not causative ${ }^{(14)}$.

The aim of this study is to assess the correlation between serum aldosterone, osteoprotegerin and fibroblast growth factor 23, glucose levels in patients with CKD (stages II-IV) in relation to cardiovascular events.

\section{Subjects and methods}

This study was carried out at Baghdad teaching hospital at Baghdad Medical city, for the period from October 2017 to February 2018, which enrolled fifty-nine patients with chronic kidney disease from stage II-IV, under supervision of a specialized physician and the diagnosis was based on serum creatinine, according to CKD-EPI Creatinine/ 2009 equation $^{(15)}$.

Fasting subjects were enrolled in this study after excluding CKD patients with a chronic liver disease, a thyroid disorder, or patient on dialysis or had at least one session of dialysis. The study was confirmed by The Local Research Ethics Committee and all subjects were provided with a written informed consent to participate in this study. Those patients were divided into three groups:

- Group1: 29 patients with chronic kidney disease stage (II-IV) with cardiovascular events.

- Group2: 30 patients with chronic kidney disease stage (II-IV) without cardiovascular event.

- Group 3:23 apparently healthy subjects (age and sex matched to that of patients).

Analysis of serum creatinine, urea nitrogen, calcium, phosphate and alkaline phosphatase were performed using the specific 
Flex ${ }^{\circledR}$ reagent cartridge /Dimension ( $\mathrm{RxL}$ Max) / SIEMENS (USA). Whereas, serum aldosterone was measured by ELISA kit, purchased by DRG Instruments $\mathrm{GmbH}$, Germany ${ }^{(16)}$. While, human fibroblast growth factor-23 ELISA kit (17) and human osteoprotegerin ELISA Kit was purchased by Cusabio Biotech Co, LTD (China) ${ }^{(18)}$. Statistical analysis of data is presented as means \pm SD. Significance was set at $p<0.05$. Cases and controls have been compared using either the t-test for independent samples, The Pearson coefficient for normally distributed variables.

\section{Results}

Pooled data of patients when compared to controls indicated that fasting serum glucose (FSG), urea, creatinine and GFR were elevated except for serum calcium levels were lowered significantly (table 1). According to CKD stages of studied group of patients , serum alkaline phosphatase (ALP) levels tend to be significantly elevated through stages II to IV compared to controls (table 2), but statistically only values of patients with stage III showed significant elevation in serum

Table1. Subjects characteristic

\begin{tabular}{|c|c|c|c|c|c|}
\hline \multirow{3}{*}{ Parameter } & \multicolumn{4}{|c|}{ Group } & \multirow{3}{*}{ P-value } \\
\hline & \multicolumn{2}{|c|}{ Patient (59) } & \multicolumn{2}{|c|}{ Control (23) } & \\
\hline & Mean & SD & Mean & SD & \\
\hline Age* (years) $^{2}$ & 60.54 & 12.49 & 50.70 & 16.21 & $\mathrm{P}=0.013$ \\
\hline Gender(M/F) & $37 / 22$ & - & $17 / 6$ & - & $\mathrm{P}=0.337$ \\
\hline Weight (Kg) & 80.56 & 16.42 & 83.85 & 13.31 & $\mathrm{P}=0.466$ \\
\hline Height* (cm) & 167.33 & 5.94 & 171.75 & 7.84 & $\mathrm{P}=0.033$ \\
\hline BMI & 28.66 & 5.18 & 28.37 & 3.72 & $\mathrm{P}=0.835$ \\
\hline FSG* (mg/dl) & 157.50 & 68.49 & 99.83 & 23.54 & $\mathrm{P}=0.005$ \\
\hline Urea* (mg/dl) & 72.52 & 29.25 & 28.70 & 9.54 & $\mathrm{P}=0.005$ \\
\hline Creatinine* (mg/dl) & 1.98 & 1.81 & 0.66 & 0.16 & $\mathrm{P}=0.001$ \\
\hline GFR* (ml/min) & 42.83 & 16.28 & 111.26 & 13.69 & $\mathrm{P}=0.005$ \\
\hline Alkaline Phosphatase ( $\mu$ kat/L) & 122.34 & 56.39 & 82.70 & 44.74 & $\mathrm{P}=0.474$ \\
\hline Phosphate (mg/dl) & 4.20 & 0.79 & 4.32 & 0.55 & $\mathrm{P}=0.513$ \\
\hline Calcium* (mg/dl) & 8.64 & 1.03 & 9.31 & 0.52 & $\mathrm{P}=0.005$ \\
\hline Sodium (mEq/L) & 140.72 & 6.31 & 142.08 & 4.29 & $\mathrm{P}=0.293$ \\
\hline Potassium (mEq/L) & 4.32 & 0.86 & 4.53 & 0.75 & $\mathrm{P}=0.231$ \\
\hline Cardiovascular disorder & 21 & - & - & - & $\mathrm{P}=0.005$ \\
\hline Smoker & 7 & - & 5 & - & $\mathrm{P}=0.979$ \\
\hline
\end{tabular}

OPG. However, data analysis according to the presence of $\mathrm{CV}$ disorders in patients compared to that of controls showed that fasting serum glucose levels of CKD patients (with and without $\mathrm{CV}$ disorder) had significantly higher values as compared to the controls $(76.5 \%$ and $29 \%$ respectively). Furthermore, patients with $\mathrm{CV}$ disease were even presented with greater fasting serum glucose as compared to those without CV disorder (Table -3). Meanwhile, serum urea levels, as well as GFR values, were significantly elevated as compared to the controls. While, serum calcium levels were significantly reduced irrespective to the presence or not of $\mathrm{CV}$ disease. But serum creatinine concentrations showed no significant variation between patients and controls. Serum Aldosterone, FGF-23, OPG levels were presented with no significant variation among studied groups (table 3 ).

Serum aldosterone levels were not altered among different studied groups according to the stage of CKD when compared to controls (figure 1). Serum FGF-23 levels were not significantly different among the different groups of patients nor from that of the control subjects, as shown in figure 2 . 
Table 2. Serum level of ALP and Osteoprotegerin through different stages of CKD patients compared to the control.

\begin{tabular}{|c|c|c|c|c|c|c|c|c|c|}
\hline \multirow{3}{*}{ Groups } & \multicolumn{8}{|c|}{ Stage } & \multirow{3}{*}{ P-value } \\
\hline & \multicolumn{2}{|c|}{ II(No.11) } & \multicolumn{2}{|c|}{ III(No.36) } & \multicolumn{2}{|c|}{ IV(No.12) } & \multicolumn{2}{|c|}{ Control (No.23) } & \\
\hline & Mean & SD & Mean & SD & Mean & $\mathrm{SD}$ & Mean & $\mathrm{SD}$ & \\
\hline $\begin{array}{l}\text { ALP } \\
\mu \mathrm{kat} / 1\end{array}$ & $\begin{array}{l}87.63 \\
\text { c } \\
\end{array}$ & 24.25 & $\begin{array}{l}126.27 \\
\mathrm{a}\end{array}$ & 63.51 & $\begin{array}{l}121.09 \\
\mathrm{a}\end{array}$ & 40.79 & 82.70 & 44.74 & 0.010 \\
\hline $\begin{array}{l}\text { OPG } \\
\mathrm{pg} / \mathrm{ml}\end{array}$ & 77.11 & 94.40 & $\begin{array}{l}112.07 \\
\mathrm{ab}\end{array}$ & 121.52 & 107.97 & 130.69 & 22.79 & 46.37 & 0.006 \\
\hline
\end{tabular}

a: significantly different from control, b: significantly different from stage IV , c: significantly different from stage III

Table3 .Variation in some studied parameters in patients compared to the control subjects according to presence of $\mathrm{CV}$ disorder or not.

\begin{tabular}{|c|c|c|c|c|c|c|c|}
\hline \multirow[t]{3}{*}{ Groups } & \multicolumn{4}{|c|}{ Patient } & \multirow{2}{*}{\multicolumn{2}{|c|}{$\begin{array}{c}\text { Control } \\
\text { No CV event }\end{array}$}} & \multirow{4}{*}{ P-value } \\
\hline & \multicolumn{4}{|c|}{ Cardiovascular event } & & & \\
\hline & \multicolumn{2}{|c|}{ Yes $(\mathrm{No}=29)$} & \multicolumn{2}{|c|}{ No $(\mathrm{No}=30)$} & \multicolumn{2}{|c|}{$(\mathrm{No}=\mathbf{2 3})$} & \\
\hline Parameters & Mean & SD & Mean & SD & Mean & SD & \\
\hline Glucose (mg/dl) & $\begin{array}{c}176.29 \\
a b\end{array}$ & $\begin{array}{c}59.0 \\
9\end{array}$ & $\begin{array}{c}128.81 \\
\mathrm{a}\end{array}$ & 47.09 & 99.83 & 23.54 & $\mathrm{P}=0.005$ \\
\hline GFR (ml/min) & $\begin{array}{c}41.62 \\
\mathrm{a} \\
\end{array}$ & $\begin{array}{c}13.7 \\
9 \\
\end{array}$ & $\begin{array}{c}48.19 \\
\mathrm{a} \\
\end{array}$ & 18.98 & 111.26 & 13.69 & $P=0.005$ \\
\hline Urea (mg/dl) & $\begin{array}{c}78.64 \\
\mathrm{ab} \\
\end{array}$ & $\begin{array}{c}26.1 \\
1 \\
\end{array}$ & $\begin{array}{c}63.16 \\
\mathrm{a} \\
\end{array}$ & 23.93 & 28.70 & 9.54 & $\mathrm{P}=0.005$ \\
\hline $\begin{array}{l}\text { Creatinine } \\
(\mathrm{mg} / \mathrm{dl})\end{array}$ & 1.76 & 0.49 & 1.65 & 0.62 & 0.66 & 0.16 & $\mathrm{P}=0.359$ \\
\hline OPG (pg/ml) & 105.65 & $\begin{array}{c}122 . \\
66\end{array}$ & 93.39 & 118.90 & 22.79 & 46.37 & $\mathrm{P}=0.233$ \\
\hline FGF-2 (pg/ml) & 50.7 & 165 & 105 & 408 & 7.8 & 3.9 & $\mathrm{P}=0.613$ \\
\hline $\begin{array}{l}\text { Aldosterone } \\
(\mathrm{pg} / \mathrm{ml})\end{array}$ & 44.80 & 3.87 & 53.95 & 32.42 & 48.09 & 20.63 & $\mathrm{P}=0.317$ \\
\hline Calcium (mg/dl) & $\begin{array}{c}8.6 \\
\mathrm{a} \\
\end{array}$ & 0.83 & $\begin{array}{c}8.49 \\
\mathrm{a} \\
\end{array}$ & 1.03 & 9.31 & 0.52 & 0.005 \\
\hline $\begin{array}{l}\text { Phosphate } \\
\text { (mg/dl) }\end{array}$ & 4.2 & 0.86 & 4.12 & 0.79 & 4.31 & 0.55 & 0.697 \\
\hline
\end{tabular}




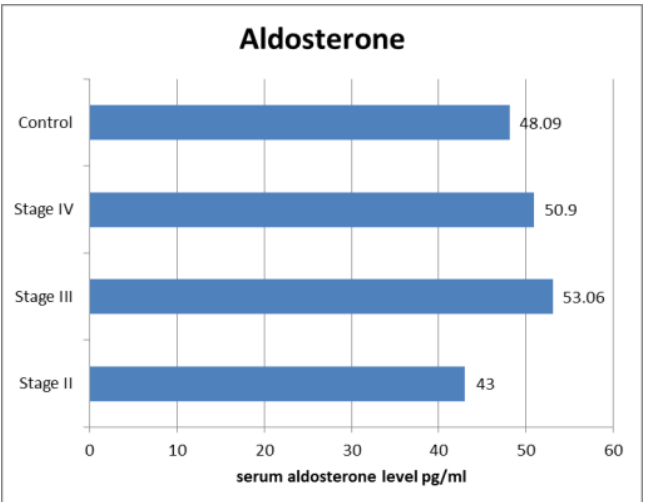

Figure 1. Serum aldosterone levels $(\mathrm{pg} / \mathrm{ml})$ among various stages of CKD patients compared to the control group

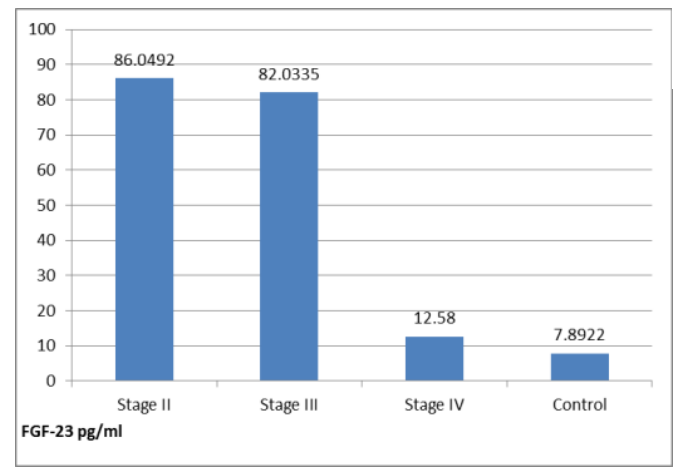

Figure 2. Serum FGF-23 levels (pg/ml) among various stages of CKD patients compared to the control group

Correlation studies for studied parameters among various groups

As shown in figure -3 , mean serum sodium levels are negatively $(\mathrm{r}=-0.353)$ correlated with serum OPG levels in CKD patients at a significance level of $(p=0.019)$. In figure 4 the mean of serum FGF-23 levels is positively $(\mathrm{r}=0.482)$ correlated with serum OPG level in CKD patients at a significance level of $(p=0.0001)$. While figure 5 showed that the mean of serum FGF-23 levels is positively $(\mathrm{r}=0.313)$ correlated with serum phosphate levels in CKD patients at a significance level of $(p=0.032)$. Aldosterone levels in CKD patients are correlated with serum urea levels $(\mathrm{r}=0.328)$, at a significance level of $\mathrm{p}=0.015$ (figure 6).

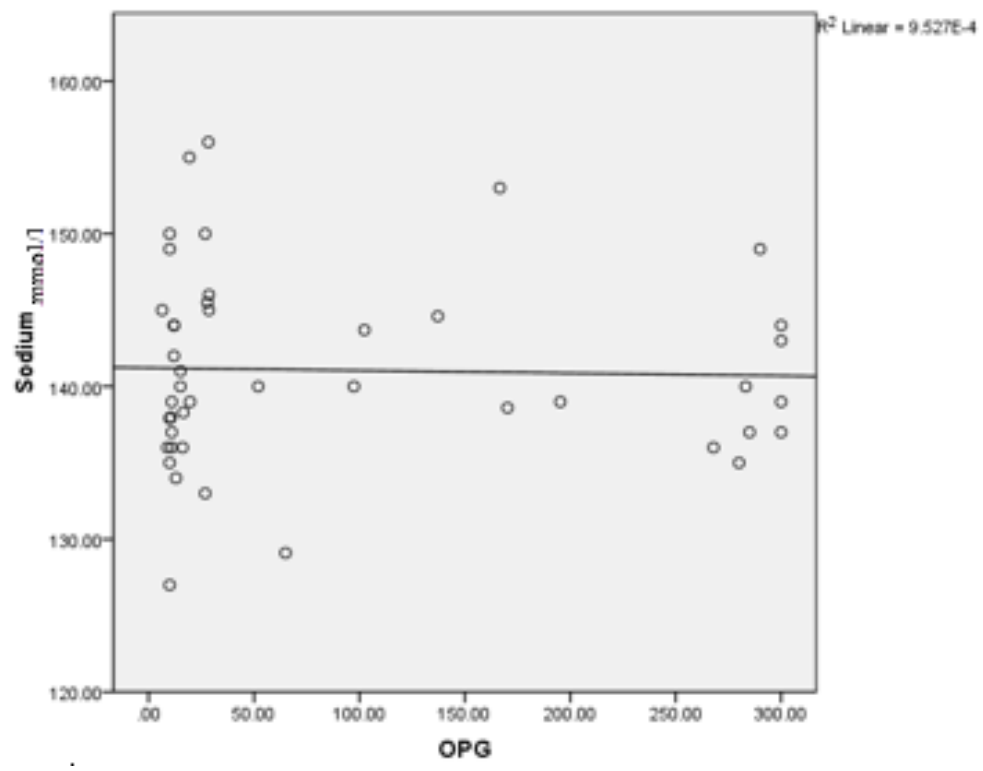

Figure 3. Correlation between Serum Sodium and OPG Levels in CKD Patients (with and without CV events ) $(\mathrm{r}=-\mathbf{0 . 3 5 3}, \mathrm{p}=\mathbf{0 . 0 1 9})$

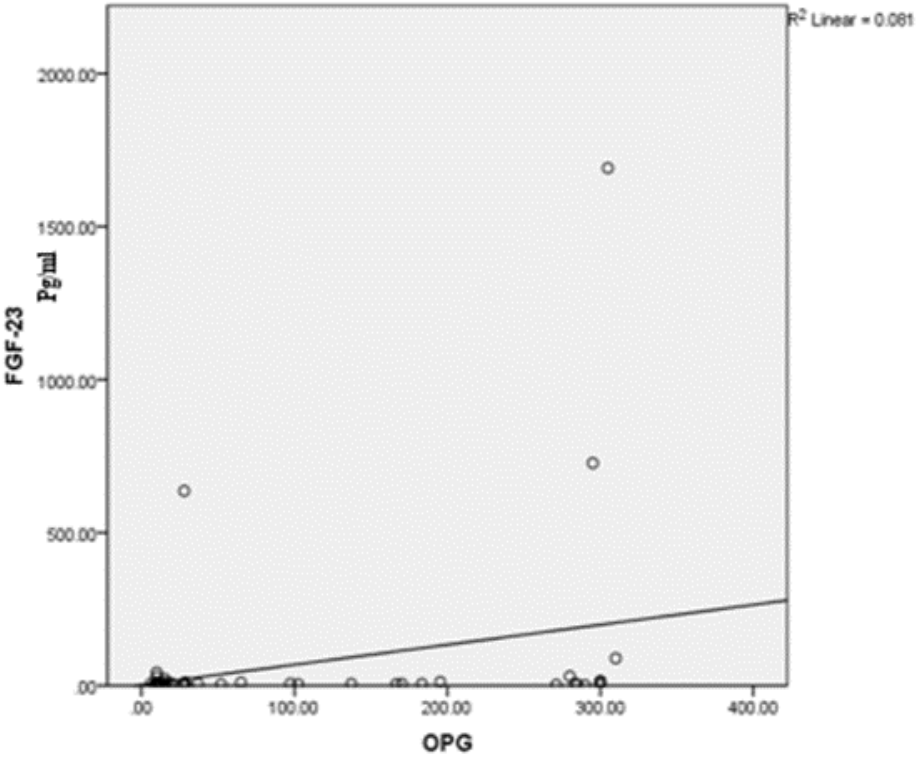

Figure 4. Correlation between Serum OPG and FGF-23 Levels in CKD Patients with or without $\mathrm{CV}$ events $(\mathrm{r}=\mathbf{0 . 4 8 2}, \mathrm{p}=\mathbf{0 . 0 0 0 1})$. 


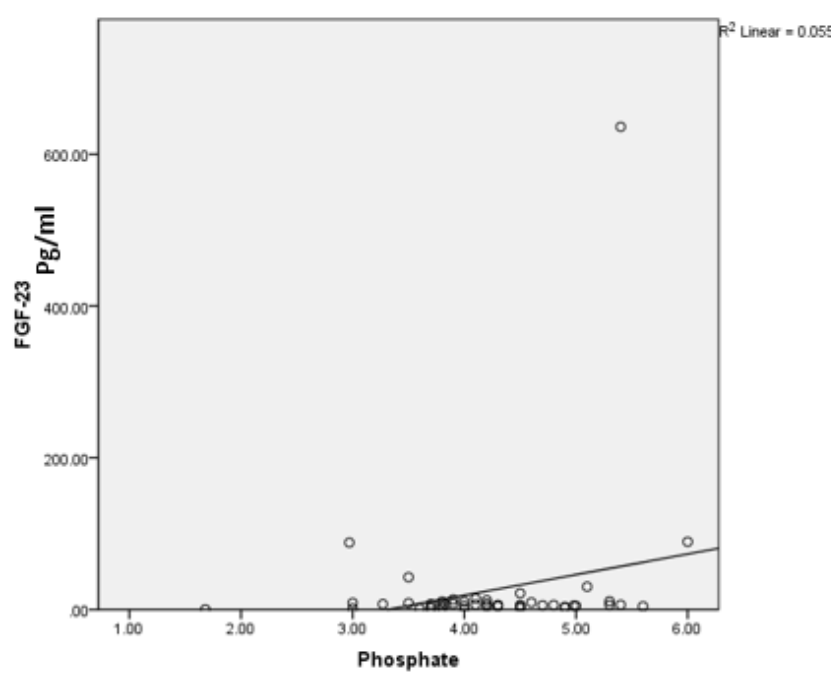

Figure 5. Correlation between Serum FGF23 and phosphate levels in CKD Patients with or without $C V$ events $(r=0.313$, $\mathbf{p = 0 . 0 3 2 )}$.

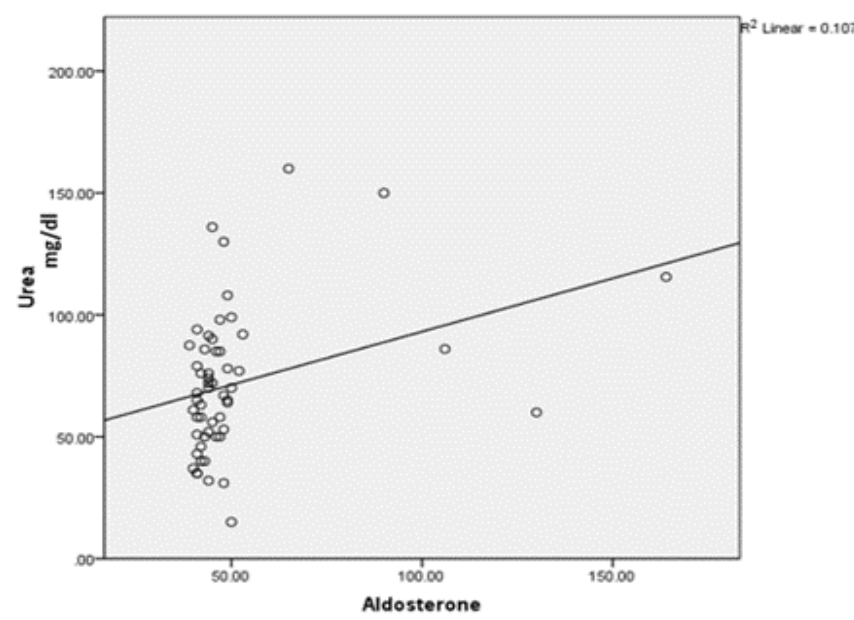

Figure 6. Correlation between serum aldosterone and urea levels in CKD patients with or without CV events ( $r=0.328$, $\mathbf{p}=\mathbf{0 . 0 1 5}$ ) .

\section{Discussion}

Effect of studied parameters on cardiovascular events Glucose

Data analysis according to the presence of $\mathrm{CV}$ disorders in patients compared to that of controls showed that fasting serum glucose levels of CKD patients (with and without CV disorder) were significantly higher values as compared to the controls $(76.5 \%$ and $29 \%$ ,respectively).Furthermore, patients with $\mathrm{CV}$ disease were even presented with greater fasting serum glucose as compared to those without CV disorder,(Table -3) and this indicates that diabetes is the main risk factor for CKD and cardiovascular disease, so the increase in glucose level will expose patients to the additional risk of cardiovascular event independent of baseline CKD present ${ }^{(19)}$.

Osteoprotegerin

Considering OPG levels only patients in stage III showed significantly higher levels from controls as well as from those in stage IV and this is consistent with what was shown in study in which serum OPG is elevated in patients with chronic kidney disease where it could predict the deterioration of kidney function, despite the fact that direct effects of OPG on kidneys are still largely not discovered ${ }^{(9)}$.

Serum sodium levels were negatively correlated with serum OPG level in CKD patients and this may be explained by correlation of $\mathrm{CKD}$ progression linked to increasing OPG serum level to hyponatremia as in large cohort study of 655,000 veterans with a mean GFR of $50 \mathrm{ml} / \mathrm{min} / 1.73 \mathrm{~m} 2$, hyponatremia was seen in $13.5 \%$ of patients and this may be due to CKD patients are at additional risk of compromised capacity to dilute or concentrate urine (Figure 3) ${ }^{(20)}$.

Serum OPG levels showed no significant variation between studied groups (table -3); these results disagreed with a study found that in patients with chronic kidney disease vascular calcification contributes to increased cardiovascular (CV) morbidity and mortality, ${ }^{(21)}$ In the present study, the results may be contributed to the small number of patients present in each group.

\section{Aldosterone}

Serum aldosterone levels in patients compared to the control levels showed no significant variation among patients with different stages of CKD and with that of the controls (Figure -1), and this is inconsistent with what has been known for decades that a plasma aldosterone concentration is elevated in CKD $^{(22)}$.

From our point of view, this was expected because all patients whether only have CKD or CKD with cardiovascular disorders are taking anti-hypertensive medications to treat either hypertension (diuretics) or other related conditions like heart failure (ACE-I), myocardial infarction (Valsartan), angina (Amlodipine) or even protecting kidney function by ACE-I or ARBs and all of which are well known that these medications affect the aldosterone serum levels ${ }^{(23)}$.

Renin-angiotensin-aldosterone system which is known to be activated in patients with $\mathrm{CHF}$, and in fact plasma renin activity also has been shown to correlate directly with mortality besides that angiotensin II is known to cause myocardial remodeling and aldosterone may increase myocardial fibrosis and necrosis in the heart, ${ }^{(24)}$ and this was not found in this study as 
there was no significant difference in aldosterone level between patients with or without CV disease, this may be contributed to all patients whether only have CKD or CKD with cardiovascular events are taking antihypertensive medications to treat either hypertension (Diuretics) or other related conditions like heart failure (ACE-I), myocardial infarction (Valsartan), angina (Amlodipine) or event protecting kidney function by ACE - I or ARBs and these medications affect the aldosterone serum levels ${ }^{(23)}$, so the result of the aldosterone level may not reflect reality and because this study is not an intervention study and not interfere with medications the patient is taking.

\section{FGF-23}

Serum FGF-23 levels were not significantly different among the different groups of patients nor from that of the control subjects, as shown in Figure -2 and likely as an appropriate compensation to help maintain normal serum phosphate concentrations in the face of declining nephron mass, in the situation where patients reach end-stage renal disease, where FGF-23 concentrations are often increased, whereas serum phosphate concentrations are only modestly increased or even normal ${ }^{(13)}$. The present study found that increased FGF-23 level is associated with left ventricular hypertrophy, fat mass, and dyslipidemia in elderly patients ${ }^{(25)}$.This positive correlation between FGF23 and mortality also is found in the general population with coronary artery disease ${ }^{(26)}$.

FGF-23 is associated with heart failure and mortality in patients with or without chronic kidney disease, Because FGF23 is regulated by phosphate (albeit in an indirect manner) and phosphate is correlated with mortality and heart failure, it is possible that this association is not causative $^{(27)}$.

While in the present result, this was not proven and this may be elaborated by the fact that there was a wide difference between minimum and maximum readings that affect statistics significance despite the fact that when we consider figure -2 for the 1 st time, there is an impression of confirmed significant difference between patients and controls data, the reason for that wide difference between minimum and maximum reading can be explained by adopting "In patients with CKD, FGF-23 concentrations are constitutively elevated and increase progressively as kidney function worsens, likely as an appropriate compensation to help maintain normal serum phosphate concentrations in the face of declining nephron mass. By the time patients reach end-stage renal disease, where FGF-23 concentrations are often increased 100- to 1000 -fold above the normal range, whereas serum phosphate concentrations are only modestly increased or even normal." ${ }^{(13)}$.Regarding urea, there was a significant difference between patients with CV disease and patients without CV disease (Table -3) and this can comply with another interesting observation in the POTIME-CHF study which is the significant rise in jugular venous pressure as quartile BUN values rose. The associated increase in renal venous pressure would increase renal interstitial pressure and activate the Renin angiotensin aldosterone system(RAAS), in addition to increase in cardiac preload and cardiac dilatation is known to be important risk factors for increased death rate in heart failure patients ${ }^{(28)}$.

\section{Alkaline Phosphatase}

Stage III and IV patients Serum ALP levels were significantly higher than that of controls (Table -2), whereas, patients with stage II serum ALP values were significantly lower than that of stage III patients and this match the new evidence states that serum ALP increases in patients with CKD, also in CKD patients without liver disease, alkaline phosphatase can be elevated in high-turnover bone disease, however measuring this readily available and inexpensive biomarker has not been considered as an individual therapeutic target of CKD-MBD ${ }^{(29)}$.

\section{Correlation studies}

Serum sodium levels were negatively correlated with serum OPG level in CKD patients $(\mathrm{r}=0.353),(\mathrm{p}=0.019)$, and this may be explained by correlation of CKD progression linked to increasing OPG serum level to hyponatremia as in large cohort study of 655,000 veterans with a mean GFR of 50 $\mathrm{ml} / \mathrm{min} / 1.73 \mathrm{~m} 2$, hyponatremia was seen in $13.5 \%$ of patients and this may be due to CKD patients are at additional risk of compromised capacity to dilute or concentrate urine (Figure 3) ${ }^{(20)}$.

While serum FGF-23 levels are positively correlated with serum OPG level in CKD patients at a significant level $(\mathrm{p}=0.0001)$ (Figure -4), this supports the theory that both OPG and FGF-23 are linked with cardiovascular mortality and this link may be mediated by direct action on the myocardium rather than by indirect effect such as arterial stiffening $^{(30)}$.

Serum FGF-23 levels are positively correlated with serum Phosphate level in CKD patients at a significant level $(\mathrm{p}=0.0001)$ (Figure -5) and this can be explained by its relation to hyperphosphatemia, a metabolic disorder that is almost universal in CKD which stimulates the release of the hormone FGF23 
from skeletal osteocytes as a role of a negative feedback loop ${ }^{(31)}$.

Serum urea levels are positively correlated with serum aldosterone level in CKD patients at significant level $(\mathrm{p}=0.015)$ (as shown in Figure-6), which could indicate an association between the decline in kidney function and corresponding elevation in aldosterone levels, and this may be due to increase in Sodium and water reabsorption correspondent to increase in aldosterone level which lead to increased reabsorption of urea and this can be seen mainly in heart failure patients, so increase sodium and water reabsorption in proximal tubule leads to increase in Urea concentration and that promote the passive reabsorption of Urea ${ }^{(32)}$.

\section{Conclusion}

Osteoprotegerin was significantly increased in stage III CKD patients as compared to control group, but no significant difference was shown between patients with or without cardiovascular events. Meanwhile, there was no significant difference between patients and controls regarding both serum aldosterone and FGF-23 levels.

\section{References}

1. Andrew S. Levey,Kai-Uwe Eckardt, Yusuke Tsukamoto, et al. Definition and classification of CKD. Kidney Int Suppl. 2013; 3:19-62

2. Ckd N . Morbidity and mortality in patients with chronic kidney disease. Am J Kidney $.2011 ; 10.018$

3. Booth RE, Johnson JP, Stockand JD, et al. Classical model of aldosterone action. Adv Physiol Educ. 2002; 26:8-20

4. Helmrich, Susan. Ragland, David. Leung, Rita. et al. ACE-I, A Corner Stone in the Treatment of Heart Failure. N Engl J Med 1994; 325:147-152

5. Karl T.Weber. Aldosterone in Congestive Heart Failure.N england J Med. 2001; 345:1689-1697

6. Anderson S, Rennke HG, Brenner BM. et al. Therapeutic advantage of converting enzyme inhibitors in arresting progressive renal disease associated with systemic hypertension in the rat. J Clin Invest. 1986;77:1993-2000

7. Nybo M, Rasmussen LM. The capability of plasma osteoprotegerin as a predictor of cardiovascular disease: A systematic literature review. Eur J Endocrinol. 2008 ; 159:603-608

8. Collin-Osdoby P, Rothe L, Anderson F, et al. Receptor activator of NF-KB and osteoprotegerin expression by human microvascular endothelial cells, regulation by inflammatory cytokines, and role in human osteoclastogenesis. J Biol Chem. 2001;. 276:20659-20672

9. Bernardi S, Toffoli B, Bossi F, et al. Circulating osteoprotegerin is associated with chronic kidney disease in hypertensive patients. BMC Nephrol. 2017; 18:1-9

10. Morena M, Jaussent I, Dupuy AM, et al. Osteoprotegerin and sclerostin in chronic kidney disease prior to dialysis: Potential partners in vascular calcifications. Nephrol Dial Transplant. 2015 ; 30:1345-1356

11. Gutiérrez OM, Mannstadt M, Isakova $T$, et al. Fibroblast growth factor 23 and mortality among patients undergoing hemodialysis. $\mathrm{N}$ Engl J Med. 2008 ; 359:584-592

12. Ketteler M, Biggar PH. As nature did not predict dialysis - What we can learn from FGF23 in end-stage renal disease. Nephrol Dial Transplant. 2009; 24:2618-2620

13. Gutiérrez OM, Januzzi JL, Isakova T, et al. Fibroblast growth factor 23 and left ventricular hypertrophy in chronic kidney disease. Circulation. 2009 ; 119:2545-2552

14. Ott SM. Bone cells, sclerostin, and FGF23: What's bred in the bone will come out in the flesh. Kidney Int. 2015; 87:499-501

15. Inker LA, Eckfeldt J, Levey AS, et al. Expressing the CKD-EPI (Chronic Kidney Disease Epidemiology Collaboration) cystatin $\mathrm{C}$ equations for estimating GFR with standardized serum cystatin $C$ Values. Am J Kidney Dis. 2011; 58:682-684

16. Borrebaeck C. Recent development in heterogenous enzyme immunoassay. Journal of solid phase Biochemistry. 1979; 41:57-8

17. Kit E Human fibroblast growth factor-23 ( FGF-23 ). 23:1-14

18. Osteoprotegerin RH, Kit OPGE RayBio ${ }^{\circledR}$ Human osteoprotegerin (OPG) ELISA Kit. 2014; 8555:1-12

19. Kazancioğlu R. Risk factors for chronic kidney disease: An update. In: Kidney Int. Suppl. 2013; 368-371

20. Dhondup T, Qian Q. Electrolyte and acidbase disorders in chronic kidney disease and end-stage kidney failure. Blood Purif. 2017;43:179-188.

21. Svensson M, Dahle DO, Mjøen G, et al. Osteoprotegerin as a predictor of renal and cardiovascular outcomes in renal transplant recipients: Follow-up data from the ALERT study. Nephrol Dial Transplant. 2012; 27:2571-2575.

22. Hené RJ, Boer P, Koomans HA, et al. Plasma aldosterone concentrations in chronic renal disease. Kidney Int. 1982; 21:98-101.

23. Mirza MAI, Alsiö J, Hammarstedt A, et al. Circulating fibroblast growth factor-23 is 
associated with fat mass and dyslipidemia in two independent cohorts of elderly individuals. Arterioscler Thromb Vasc Biol. 2011; 31:219-227.

24. Parker BD, Schurgers LJ, Brandenburg VM, et al. The associations of fibroblast growth factor 23 and uncarboxylated matrix Gla protein with mortality in coronary artery disease: The heart and soul study Ann Intern Med. 2010; 152:640-648.

25. Mulatero P, Rabbia F, Milan A, et al. Drug effects on aldosterone/plasma renin activity ratio in primary aldosteronism. Hypertension. 2002; 40:897-902.

26. Factor $P$ Role of Diminished Renal Function in Cardiovascular Mortality. J Am Coll Cardiol. 2006 ; 47:1-8.

27. Ott SM. Bone cells, sclerostin, and FGF23: What's bred in the bone will come out in the flesh. Kidney Int. 2015; 87:499-501.

28. Schrier RW. Blood urea nitrogen and serum creatinine: not married in heart failure. Circ
Heart Fail. 2008; 1:2-5.

29. Kovesdy CP, Ureche V, Lu JL, et al. Outcome predictability of serum alkaline phosphatase in men with pre-dialysis CKD. Nephrol Dial Transplant. 2010; 25:30033011 .

30. Ford ML, Smith ER, Tomlinson LA, et al. FGF-23 and osteoprotegerin are independently associated with myocardial damage in chronic kidney disease stages 3 and 4. Another link between chronic kidney disease-mineral bone disorder and the heart. Nephrol Dial Transplant. 2012; 27:727-733.

31. Demer LL, Tintut Y. Inflammatory, metabolic, and genetic mechanisms of vascular calcification. Arterioscler Thromb Vasc Biol. 2014; 34:715-723 .

32. Lindenfeld J, Schrier RW. Blood Urea Nitrogen. J Am Coll Cardiol. 2011; 58:383385 . 